Pediatric Bipolar and the Media of Madness

Jonah Bossewitch, PhD [Candidate]

Columbia University 


\begin{abstract}
This past decade has witnessed an explosive rise in the controversial diagnosis of pediatric bipolar and the prescription of anti-psychotics to children. Has the behavior of American children grown more irritable and defiant, or has adult judgment of their behavior changed? How can we effectively study and explain these dramatic transformations in judgment and behavior? This article proposes a hypothesis that explains many of these developments and lays out a research program for a continuing investigation of these urgent questions. The paper highlights the controversy around the diagnosis of pediatric bipolar and the emerging relations between the media of surveillance and structures of social control. It explores connections between the interactive media landscapes inhabited by youth, the behavioral expectations imposed on them in schools, and the role of psychoactive drugs in mediating this tension. Finally, the article details the intersections between media, communications, and madness studies and proposes a research agenda for studying this controversy using approaches drawn from these disciplines.
\end{abstract}

Keywords: cultural studies, media ecology, psychiatry, psychology, antipsychotics, prodromal, surveillance, pediatric bipolar 


\section{Pediatric Bipolar and the Media of Madness}

The notion of "fact," let us recall, had the disadvantage of not taking into account the enormous work of shaping, formatting, ordering, and deducing, needed to give the data a meaning they never have on their own (Latour, 2004, p. 117).

\section{Atypical Childhoods}

This past decade has witnessed a profound shift in our judgment of behavior in children in the US, as childhood itself is increasingly pathologized. The explosive rise in the controversial diagnosis of pediatric bipolar has received sparse coverage in the mainstream media, despite the scandalous activities that psychiatrists and pharmaceutical company executives have perpetrated to promote the existence and treatment of this condition (Carey, 2007; Wallace-Well, 2009). We have moved beyond the era of prescribing kids Ritalin because they can't stop fidgeting. With the profusion of bipolar diagnoses in children and its common treatment with powerful and dangerous atypical anti-psychotic medication, significant numbers of adolescents and teens are being chemically swaddled and sedated. Parents are under increasing pressure from teachers and other parents to "correct" their children's behavior with potent mind and mood altering drugs, often with devastating side-effects (Yan, 2008).

Has the behavior of American youth grown more irritable and defiant, or has the adult judgment of their behavior changed? How can we explain the variations in diagnoses around the globe? Why are similar childhood and adolescent behaviors diagnosed in some settings and not in others? If there is a dramatic shift in youth behavior, what factors and dynamics might be precipitating these changes? How can we effectively study and explain these dramatic transformations in judgment and behavior?

This article proposes a hypothesis that explains many of these developments and lays out a research program for a continuing investigation of these urgent questions. The paper first highlights 
the controversy around the diagnosis of pediatric bipolar and the emerging relations between the media of surveillance and structures of social control. It then explores the connections between the interactive media landscapes inhabited by youth, the behavioral expectations imposed on them in schools, and the role of psychoactive drugs in mediating this tension. Finally, the article catalogs the intersections between media, communications, and madness studies and proposes a research agenda for studying this controversy using approaches drawn from a multidisciplinary perspective.

Media and communications theorists are especially well positioned to research these questions. Their disciplinary methods and experiences can spearhead the critical interrogation of the representations of pharmaceuticals and mental illness in advertising, popular culture, and the press. These methods are also well suited to study how these controversies are framed and how they unfold over time and influence public opinion. The media and communicative environments that we inhabit shape our experiences, perspectives, and behaviors (McLuhan, 1964; Ong, 1982). These environments are undergoing revolutionary changes, and media and communications scholars can offer insights into some of the correlated changes in identity formation and social interactions (Manovich, 2002). Additionally, as more authoritative judgments are made through the interpretation of records gathered through institutional surveillance, diagnostic constructs and practices are subtly changing in response to this new form of scrutiny. Finally, psychoactive drugs distort phenomenological experiences in ways that can be productively analyzed as a form of mediation. Just as traditional media mediate communications between senders and receivers, psychoactive drugs modulate cognitive and perceptual apparatus, and effectively mediate direct experiences of reality. Like traditional media, these drugs shape our experiences, perspectives, and behaviors - our ways of seeing and being in the world.

\section{Evidence Based Child Abuse}


Before analyzing statistics and trends, a few powerful anecdotes will vividly illustrate the contours and extent of this growing controversy.

Consider the case of Rebecca Reily, a 4-year-old girl in Boston who died on December 2006 after an overdose of the anti-psychotic Seroquel, administered by her parents (Couric, 2007). Her parents are currently facing first-degree murder charges, but they claim to have been following doctor's orders. Rebecca's psychiatrist, Dr. Kayoko Kifuji, diagnosed her with attention deficit and hyperactivity disorder and bipolar disorder when she was just $2 \frac{1 / 2}{2}$ years old, and prescribed a powerful cocktail of psychotropic medications. Dr. Kifuji's license was not suspended, although she voluntarily suspended her practice pending the resolution of the outstanding civil and criminal charges (Wen, 2009). Her hospital has issued the statement: "The care we provided was appropriate and within responsible professional standards" (Creamer \& Mishra, 2007).

Sadly, this case is not an isolated occurrence. Reports recently surfaced about another 3-yearold girl, Destiny Hager, who died in April 2006 of complications resulting from known side effects of the antipsychotics Seroquel and Godeon (Carpenter, 2009). An autopsy of the 38-lb girl revealed "antipsychotic drugs present in concentrations considered therapeutic in adults" (Carpenter, 2009).Her psychiatrist, Vernon Kliewer, who has been practicing children's psychiatry for over 50 years, was investigated by the Kansas Board of healing arts for his treatment of Destiny and five other children ages 2-5. Kliewer negotiated a settlement that didn't require him to admit any wrongdoing, and he has voluntarily stopped treating patients under age 6 (Carpenter, 2009).

In January 2008, PBS Frontline aired an hour-long documentary called The Medicated Child, profiling the lives of three children diagnosed between 4-6 years old with bipolar disorder (Garviria, 
2008). The children and their families were all struggling with devastating side effects and complications, such as tardive dyskinesia and extreme weight gain, resulting from their treatment. The documentary argued that a massive public health experiment is currently being conducted on the nation's youth, without anyone's informed consent (Garviria, 2008).In one scene in the documentary a mother was feeding her son corndogs, Gatorade, Goldfish crackers, and cookies, while she complained on-camera about his erratic hyperactive behavior. In another, a young girl was goaded by her psychiatrist into sharing her violent fantasies, though the doctor fails to explore the connections to her father's trauma as an Iraqi war veteran. In yet another, a mother makes an appointment to reduce her son's medications but is told by their psychiatrist that drugs are the only therapeutic option. She leaves the office with an additional prescription for Xanax to relieve her son's first day-of-school anxiety.

In May 2009 CBS news reported on a class action lawsuit brought against Jansen (owned by Johnson and Johnson) for the side effects of their antipsychotic Risperdal causing gynecomcastia, or male breast growth in ten young boys (Couric, 2009). Boys ranging from 4-14 years old have been prescribed Risperdal for ADHD and bipolar disorder, and have developed female breasts that can only be treated with mastectomies.

These stories are horrifying, but they are not exceptions. They are indicators of the systematic marketing and lobbying campaigns to expand the diagnostic criteria, and to brand children with a new disease. In April 2008, Florida health officials instituted a perfunctory review process for all Medicaid prescriptions of antipsychotics to children under 6 (Hundley, 2009). The previous year, 23 infants under 1 were prescribed this class of drugs, and public pressure was mounting to regulate their use. Since the new rule was enacted, prescription rates in Floridian children younger than 6 have dropped from 73 children to 28. But, around the country their usage continues to climb (Hundley, 2009). 
During this period of rampant increase in the treatment of pediatric bipolar, it should be noted that the diagnosis does not even exist in the current version of the Diagnostic Statistical Manual, DSMIV-TR, the official guide to mental disorders published by the American Psychiatric Association Association, A. P. (2000). Between 1994 and 2003 the diagnosis of bipolar in American children and adolescents has jumped $4000 \%$ (Carey, 2007). The antipsychotics administered to these children have been prescribed "off-label" (Shekelle et al., 2007) Doctors are permitted by law to prescribe any medication they judge helpful, but the FDA must approve a drug for a particular treatment before the pharmaceutical companies are allowed to market that drug for that usage. Numerous scandals, such as the Eli Lilly's Vivi Zyprexa campaign, have involved drug companies specifically marketing drugs for off-label uses (Dawdy, 2007). A recent study found that between August 2006 and July 2007, 37\% of prescriptions for antipsychotic drugs were written by family doctors - general practitioners, not psychiatric specialists (Morgan, 2009).

In Summer 2008 the FDA legislated pediatric bipolar into existence, so that clinical trials could proceed prior to the publication of the DSM-V in 2013 (Dawdy, 2008). The FDA evaded inquiries demanding a definition of the disorder, and finally supplied very thin evidence for its existence (Dawdy, 2008). In 2007 the FDA approved Johnson \& Johnson's Risperdal for use in children as young as 10, and the approval for Bristol-Myers Squibb's Abilify followed in 2008 (Office of the Commissioner, 2007). This year an FDA advisory panel backed the expanded use of three commonly prescribed antipsychotic drugs for children—Lilly's Zyprexa, AstraZeneca's Seroquel and Pfizer's Geodon (Dawdy, 2009). Side effects including massive weight gain, metabolic disorders, tardive dyskinesia, and diabetes are common amongst this class of drugs (Ücok \& Gaebel ,2008). The longterm effects on developing children are still unknown (Heavy, 2009). 
Even within the psychiatric community, there is little consensus about pediatric bipolar diagnoses and treatments. Back in 2000, psychiatrist Dr. Lawrence Diller wrote the following in a story published by Salon.com:

Diagnosing bipolar disorder in children as young as 3 has become the latest rage. It justifies using a host of meds to treat very difficult-to-manage, unhappy children. The old-line drug, lithium, has been replaced by newer, untested (in children) mood stabilizers like Neurontin or Depakote as a first-choice intervention for pediatric "manic depression". Finally, a new class of anti-psychotic medications - the most popular these days is Risperdal—is heralded as the ultimately effective treatment for a number of diagnoses whose common features are not hallucinations or psychosis, but severe acting-out behaviors.

More than 200,000 children receive anti-psychotic medications, mostly to control unruly behavior rather than to treat hallucinations or other symptoms of schizophrenia.

No other society prescribes psychoactive medications to children the way we do. We use 80 percent of the world's stimulants such as Ritalin. Only Canada comes close to our rates, using half, per capita, the amounts we do. Europe and industrialized Asia use one-10th of what we do. Psychiatrists in those countries are perplexed and worried about trends in America. The use of psychoactive drugs other than Ritalin for preteen children is virtually unheard of outside this country (Diller, 2000).

A handful of academic researchers (Crystal, Olfson, Huang, Pincus \& Gerhard, 2009), independent journalists such as Philip Dawdy of FuriousSeasons.com (Dawdy, 2007) and bloggers have been closely following these developments. They have tracked and documented the dramatic increases in 
childhood diagnoses and prescriptions, and raised concerns over the long-term safety of these drugs due to their serious side effects and known developmental and metabolic issues. They have pointed out the discrepancies between American and international diagnoses (Lane, 2009), as well as the more aggressive prescription patterns for children covered by Medicaid versus those covered by private insurance (Martin et al., 2002) . But the surge in diagnoses and prescriptions continues to grow (Wilson, 2009).

\section{Pathological Soothsayers and Permanent Records}

If these trends are not sufficiently jarring, the future is even more disconcerting. Psychiatry continues to innovate, and is poised to push beyond pathalogizing formerly normal behaviors by pathalogizing risk with the growing rise of prodromal diagnoses. A prodrome is a symptom or group of symptoms that appears shortly before an acute attack of illness. The etymology of this word traces back to a Greek term meaning 'running before' or precursor (Prodromal, n.d.). An emerging trend in clinical psychiatry is the appropriation of this concept under the paradigm of "early intervention in psychosis" for "at risk" patients. Psychiatrists are preventively diagnosing mental illness and treating people prior to them exhibiting any behavioral symptoms. Children and adolescents are especially vulnerable to prodromal diagnoses, and much of the research and marketing is directed at preventing children from developing mental illnesses. The Editor in Chief of the peer-reviewed journal Current Psychiatry identifies early diagnosis and intervention as one of the top six trends affecting psychiatric practice:

Earlier diagnosis and early intervention. The past decade has witnessed a surge of progress in identifying individuals at high risk for psychosis or mood disorders. The "prodrome" has become a fertile area of research, with a focus on early "treatment" even before the clinical syndrome of schizophrenia or mania appears. The goal is to try to delay, modify, or ameliorate 
incipient serious mental illness by using both pharmacotherapy and psychotherapy (Nasrallah, 2009).

Instinctively, preventative health care seems like a good thing. Western medicine is often criticized for primarily responding to acute crises, instead of proactively promoting health and wellbeing. However, the reductionist flattening of minds into brains leads to categorical errors which pervert the Hippocratic principle to "do no harm". Applying the medical paradigm to the treatment of risks, instead of disorders, stretches the dangerously elastic diagnostic net beyond the breaking point.

Analogies between mental conditions and diseases of the body, such as diabetes, measles, or heart failure, are often the point of departure for proponents of prodromal treatment. However, these casual comparisons mask assumptions and disguise relevant disanalogies. The pathologization of diverse mental states remains controversial, unlike life threatening viruses or organ failures. Furthermore, there is currently no casual theory explaining why some people's psychological experiences degenerate into crisis. Arguably, there can never be such a theory until we make significant progress towards resolving the mind/body problem, (a.k.a. the "hard problem" of consciousness). Without a causal theory explaining the transitions between mental states, all prodromal diagnoses of mental conditions are necessarily speculative correlations.

The roots of prodromal diagnosis of mental conditions can be traced back to work on the prodromal identification of schizophrenia:

What is needed is not the early diagnosis of schizophrenia, but the diagnosis of pre-psychotic schizophrenia. We must learn to recognize that state of mind which will develop into schizophrenia unless appropriate measures are taken to prevent deterioration (Meares, 1959, p. $55)$. 
However, the identification of reliable predictors of schizophrenia has proven to be notoriously difficult and conceptually slippery:

Identifying symptoms or signs that reliably predict onset would obviously aid attempts to prevent mental disorders. Such specific predictors do not currently exist. In fact, one could argue that if any such risk factors were identified they would be conceptualized as early phenomena of the disorder itself... The nonspecific nature of these common features is notable (Yung et al., 1996, p. 285).

The clinical gaze embodied in the pages of the DSM has always been rooted in behaviorismthe symptoms it defines are all observable behaviors. The trend towards prodromal mental diagnoses is flawed precisely because it cedes even more power to an already cold and inhumane apparatus, which fails to listen to the voices of the people it claims to treat (Whitaker, 2003). The risks of preemptive discipline and prescriptive moral judgment rhymes with eugenics, and are simply too great and damaging for this practice to continue (Foucault, 1988). Patients, especially children, are being indicted on the basis of hereditary factors, thought crimes, and innocuous deviant behavior. In a distinctly Orwellian twist, patients exhibiting symptoms are psychotic, while those that don't exhibit symptoms (yet) are prodromal (Orwell, 1961).

Furthermore, the psychopharmacological treatments prescribed for these prodromal diagnoses are physically dangerous and psychologically damaging. As already discussed, the atypical antipsychotics that are often prescribed in these circumstances have been linked to excessive weight gain, metabolic disorders, and diabetes (Yan, 2008). The stigma attached to these diagnoses is also emotionally threatening. Advertising campaigns such as the award winning "Prescribe Early" poster, "which used a macabre abandoned wallet, teddy bear and keys on a barren street to reposition a drug 
that was being used too late to achieve its maximum benefits" (Rosenberg, 2009), have heightened the pressure to preventively prescribe dangerous medication, before it is too late.

Children and teens often traverse defiant emotional terrain on their journey of self-discovery and becoming. Adult disapproval towards behaviors (smoking, drinking, inappropriateness, and irritability) and appearances (fashion, body piercing, hair style) has increasingly taken the form of chemical discipline, with psychiatry's permission and blessing (White, Anjum, \& Schulz, 2006). Defiant teenagers are threatened with prodromal diagnoses based on their alternative fashion choices and misunderstood behavior. Smoking and substance abuse have already been associated with bipolar in teens, and are already being used as diagnostic criteria (Wilens et al., 2008). A recent article in the American Journal of Psychiatry introduces the following patient and explores if this teenage girl is prodromal for schizophrenia:

A 13-year-old girl, currently in the eighth grade and with a history of attention deficit hyperactivity disorder, was brought by her mother to a university-affiliated outpatient psychiatric clinic after a gradual decline in her academic performance was noted... She had tasted alcohol in the past but denied current use. She had also used marijuana a half-dozen times... her parents claimed that she had been withdrawn and had appeared sad and that at times they needed to prompt her to take a shower. She had a maternal aunt with bipolar affective disorder and a great uncle who had been institutionalized for unknown reasons... she was dressed in Goth attire, including a black T-shirt with images of letters dripping blood; she had dyed black hair. Her affect was blunted but was slightly more animated when her parents left the room. She denied thoughts of suicide. She reported occasionally hearing whispering voices calling her name and saying that she is worthless. She also reported the belief that her friends did not like her as much as they had...(White, et al., 2006, p. 376) 
The trend towards prodromal diagnoses coincides with a parallel trend in society towards the auto-classification and prediction of citizen and consumer behavior (Andrejevic, 2007). Governments and corporations have a strong interest in predictive behavioral models of every person they monitor (Stanley \& Steinhardt, 2003). These systems are currently making their way off the lab bench, and into production systems (Robert, 2005). Already, algorithms to automatically classify human behavior based on nothing but the video stream have been deployed in nursing homes, casinos, and the Olympics. As computers scientists and engineers contend with the challenge of automatically classifying the full range of human behaviors, the DSM's ready-made ontology may prove too convenient to challenge. Just as code enacts law, diagnostic labels are on their way to being represented in software, where their embodiment will take on a life of its own. .

Such a future for psychiatry is quite disturbed. Prodromal treatment is the latest progression in an ever-constricting system of social control. Preventative psychiatric treatment hints at forms of control that resonate with fears of omniscient surveillance, and we can begin to glimpse how grotesque these practices might become in an era of pervasive surveillance and electronic medical records. Pathologizing the neurologically diverse is bad enough. Extending this attitude, and treatment, to those at risk of neurological diversity is ethically dubious and threatens our freedom.

\section{Means, Motives, and Opportunities}

To fully appreciate the financial motives behind the expansion into these new markets it is essential to understand the role of intellectual property law in this political economy. Pharmaceutical companies are granted patents on their discoveries, guaranteeing them a monopoly that is supposed to incentivize innovation. Putting aside the ethics of controlling potentially life saving drugs, all of these 
patents eventually expire, leaving drug companies with a gaping shortfall in profits to fill (Hari, 2009). Expanding diagnostic criteria for treatment extends the patent clock, and gives drug companies more time to reap bumper profits from their drugs.

It is notable that the rise in pediatric bipolar, and its standard treatment with atypical antipsychotics, coincided with many of the drugs used to treat hyperactivity coming off patent. Eli Lilly's own internal memos, revealed upon discovery in a class action suit against Zyprexa, clearly indicate that Lilly had initiated internal marketing campaigns to promote the prescription of Zyprexa (a powerful and dangerous anti-psychotic), for seniors with dementia, and children with behavioral disorders (Dawdy, 2007). At the time of these internal campaigns, Zyprexa was not approved for either of these populations or indications (Dawdy, 2009). The memos are explicit about wanting their sales representatives to target general medical practitioners, not just psychiatrists (Dawdy, 2007). Were there simply not enough schizophrenics to satisfy the insatiable financial ambitions of the company, so they expanded their diagnostic net to include more potential customers?

In the wake of a series of scandals involving prominent academic psychiatrist's conflicts of interest, kickbacks, and fraud, Senator Charles Grassely has begun investigating the influence of drug companies on the practice of medicine (Kweskin, 2010). One of the most egregious perpetrators is Harvard University psychiatrist, Joseph Beiderman, a leading champion of the pediatric bipolar diagnosis. Beiderman failed to disclose to his employer over $\$ 1.6$ million in consulting fees from drugmakers earned between 2000 and 2007 (Harris \& Carey, 2008). He has also been accused of submitting ghostwritten papers for publication in scientific journals, and for accepting payments to participate in Johnson and Johnson's Center for Education in the Study of Pediatric Bipolar (Harris, 2008). At one point, Biederman assured Johnson \& Johnson that planned studies "will support the safety and effectiveness of risperidone in this age group," effectively guaranteeing the outcome of the 
study before it was even conducted (Harris, 2009). [

A campaign trumpeting the "extreme shortage of child psychiatrists" is currently running across the Internet, specifically targeting medical students (Kaplan Medical, n.d.). An anticipated shortage of child psychiatrists, based on the Surgeon General Report's claim that "about 20 percent of children are estimated to have mental disorders with at least mild functional impairment (U.S. Surgeon General, 1999)." Legislation is currently winding its way through congress which will forgive student loans for doctors who enter child psychiatry (Child Health Care Crisis Relief Act, 2009).

\section{Towards a Hypothesis of Behavioral Revolutions:}

\section{Spirited Students and Explosive Communications}

The available evidence that children's behavior is dramatically different than prior generations is inconclusive. It is entirely plausible that our adult standards and judgments have changed, not their behavior. However, if we really are witnessing a rise in childhood irritability and behavioral issues in the classroom, there are several very important research questions we need to be asking. We are in the midst of a monumental revolution in communications and media, and the forces we are unleashing have barely begun to be cataloged and appreciated (Benkler, 2006; Carey 1992; Castells, 1996; Peters, 2001). We need to study the interplay between the media environments we are immersed in, and our day-to-day experience of the world - the tensions between these worlds, and our strategies for mediating these tensions.

Consider the impact of boredom and stress on the K-12 demographic. Outside of school, many of our children are immersed in hyper-stimulating, interactive, participatory play. As Steven Johnson has argued, everything bad for them is good for them (Johnson, 2005). Today's youth are playing incredibly sophisticated video games, consuming complex media, and participating in ever-accelerating 
communication explosion. Meanwhile, in most classrooms they are being lectured at by teachers performing an $18^{\text {th }}$ century, colonial, "banking model" of education (Freire, 2000). Generally speaking, many of these students are bored out of their wits. What impact is the media and communications revolution having on the experiences and behaviors, of childhood, and how does education need to adapt to this context? While I am not advocating that all instruction should become entertainment, it is crucial to recognize that many of today's students are unprepared to concentrate or focus for sustained periods of time. The capacity to concentrate and study cannot be presumed as a baseline skill, if it ever was before.

Students are also under an inordinate amount of stress. The No Child Left Behind Act (2002) has homogenized curriculum across the country and mandated an endless flow of standardized tests. Surveillance is on the rise, and many public schools are now outfitted with security guards and metal detectors. Preliminary research has demonstrated that these factors actually lead to increased stress and anxiety, instead of providing safe and secure environments as they are intended (Weiss, 2006). The emotional climate at these schools is deteriorating rapidly, but without the proper instruments to assess these factors, it is quite difficult to address them (Center for Social and Emotional Education, n. d.).

Compound these factors with the elimination of art, music, recess, and even physical education in many public school systems (Center for Social and Emotional Education, n. d.) and the conditions for restless agitation are in place. If we factor in poor nutrition and sleep deprivation the arrows of causation become even stronger. Pilot studies have shown that improved nutrition can reduce violence and behavioral unrest in prisons and schools (Laurance, 2008). There has also recently been research demonstrating that sleep deprivation leads to hyperactivity and irritability, not the other way around, as was long believed (Brody, 2007). 
Finally, teachers are no longer formally responsible for teaching children how to recognize and manage their own emotions. These reflective skills are simply not a part of the curriculum, and as friction and tension emerges, the issues are dealt with as disciplinary or psychiatric matters, not emotional or social.

In response to these profound failures in the educational system a frightening pattern has emerged. These problems are currently being mediated through very powerful psychiatric medications, which slow down children by dulling their minds and sedating their bodies. Some of the most independent, creative, and sensitive students are being selected for their deviance, and drugged until they conform to an authoritative standard. Parents are under intense pressure from schools and other parents to "correct" their children's behavior. These children's behaviors and experiences are being molded and shaped by the psychotropic drugs they are forced to consume. Children who are diagnosed with Attention Deficit Hyperactivity Disorder, Conduct Disorder, Oppositional Defiance Disorder, Depression, Bipolar Disorder, Anxiety Disorder, Shyness Disorder, and Autism, are being prescribed anti-psychotics at alarming rates.

It is unclear what the ethical response to disruptive behavior in the classroom ought to be. Few of us want to live in a world 20 years from now run by people raised on potent psychiatric medications. According to Lloyd deMause, a prominent psychoanalyst and historian of childhood, child abuse extends deeply and broadly throughout human histories and cultures, and is far more widespread than most of us are prepared to admit (Demause, 1982). The notion that parents and teachers are receiving a blessing from medical authorities to 'shut their kids up' is an important backdrop against which to consider these practices. 
We need to aggressively explore educational models that support and embrace diverse learning styles. As Clayton Christensen argues in Disrupting Class, we need to begin to embrace studentcentric learning models in response to the individual needs of each student (Christensen, Johnson \& Horn, 2008). Instead, we seem to have chosen a homogenizing strategy, and are forcing all students to conform to a monolithic learning style and uniform standards of assessment, even if it requires powerful drugs to modify their personalities and dispositions.

\section{Labels, Facts, and Values}

The proponents of pediatric bipolar often rely on rhetorical sleights of hand to bolster their case by strategically framing the terms of the debate. They conflate facts with value judgments, and wield these facts in an attempt to short-circuit and shut down all debate. They cite neurotransmitter activity, brain imaging, and heredity as proof that patients are "sick" when, at its best, this evidence signifies difference and diversity. Even if biochemistry, neurology, and genetics can be convincingly correlated with diverse mental states, the judgment of these states as ill or diseased involves an additional unacknowledged leap of faith. Spokespeople for the prevailing medical model claim an objective view from nowhere, but their vantage point is loaded with subjective value judgments. Many are so thoroughly immersed in the disease paradigm that they don't even recognize the implicit subjectivity in these pronouncements. These flagrant distortions are most visible at the diagnostic boundaries, such as when moody toddlers and defiant adolescents are diagnosed as diseased.

All too often, purportedly neutral facts are loaded with value judgments, but presented as incontrovertible on the basis of their 'facthood'. This perspective does not deny the possibility of varying degrees of confidence in different assertions, but we must demand recognition of the inevitable 
entanglement of subjectivity in our descriptions of a complex and contingent world. The real world implications of the misuse of language and rhetoric are serious and potent (Davis, 1997).

As Mary Kurchinka explains in her bestselling book, Raising your Spirited Child, language and labels are extremely powerful (Kurcinka, 1998). We always have a choice to describe identical behaviors with words that carry different connotations. Are children acting: explosive/spirited, demanding/high standards, unpredictable/flexible, loud/enthusiastic, argumentative/opinionated, stubborn/assertive, nosy/curious, wild/energetic, manipulative/charismatic, impatient/compelling, anxious/cautious, explosive/dramatic, picky/selective, distractible/perceptive (Kurcinka, 1998)? These simple descriptive choices construct and perpetuate vastly different worlds. They communicate expectations as well reinforce condemnation or support.

\section{Mad Controversies and Diagnostic Media}

What are some of the strategies, methods, and approaches we can marshal to study these complex phenomena? The controversies around pediatric bipolar are tangled and emotionally charged. The traditional human, social, and life sciences can and should bring the full force of their disciplines to bear on these questions. Additionally, media and communications studies are positioned to offer unique and valuable perspectives on these issues (Peters, 2009).

Building on work in Science and Technology Studies and Bruno Latour's interpretation of Actor-Network-Theory (Latour, 2005), scholars have begun to pioneer techniques for mapping and visualizing contemporary public controversies (Venturini, 2009). At their core, these techniques involve “just" observing and describing, but as Tommaso Venturini elaborates in his description of these methods, "just" is deceptively simple word. He claims that "the three commandments of sociological 
observation according to the cartography of controversies [are]: 1. you shall not restrain your observation to any single theory or methodology; 2. you shall observe from as many viewpoints as possible; 3. you shall listen to actors' voices more than to your own presumptions." (p. 5). A comprehensive cartography of the controversies around pediatric bipolar is beyond the scope of this essay, but we can actively imagine a future project which fills in the cartographic detail of the territory we have surveyed.

The controversies surrounding pediatric bipolar are fertile sites for studying the dynamics of public controversies since critics have engaged the issues on multiple conceptual fronts using a variety of tools and media. Like many controversies involving public heath and psychiatry's clinical gaze, the issues surrounding pediatric bipolar provoke debates about the integrity of rhetoric, science, and politics. As Bradley Lewis rigorously demonstrates in Moving Beyond Prozac (2006), the discourses participating in this controversy encompass multiple perspectives which span these dimensions. The rhetorical critiques are theory-laden challenges to the ideological frames which are constructed and mobilized to describe the issues. The scientific critiques accept (or bracket) the dominant research paradigms and concentrate on questioning the validity of the research claims, on their own terms. Finally, the political critiques accept the narrow focus of the research, and instead question processes such as the construction of the research agenda, the voices involved in formulating policy recommendations, and the conflicts of interest and aggressive marketing practices that influence behavior and perception. These dimensions often overlap, and are difficult to disentangle completely in debate or analysis. However, it is important to clarify our assumptions when studying this controversy.

The controversies surrounding pediatric bipolar suffer from a lack of clarity regarding the 
essence(s) of the debate. Many of the arguments against the diagnosis of children and adolescents with bipolar disorder apply with equal force to adult psychiatric diagnoses. Activists have struggled for decades (Coleman, 2008), if not centuries (Whitaker, 2003), to resist the plodding advance of psychiatric biopower. Challenging psychiatric methods and paradigms, questioning the validity of pharmaceutical research, and protesting the political processes of mental health policy is nothing new. This research agenda should be designed to answer the following questions:

What is the special significance of children at the center of this particular controversy? What are the underlying economic and psycho-social forces motivating the steady expansion of diagnostic criterion and driving us to pathologize the full range of human experience? What is the relationship between contemporary media and madness? Why has this controversy provoked such a passionate outcry from psychiatrists, activists, and independent journalists, but received scant attention from the mainstream media or the Federal government? Are alternative explanations for purported shifts in the behavior of children and adolescents being adequately explored? Whose voices and perspectives should be taken into account in deciding these questions?

Psychiatric diagnoses and psychotropic drugs directly mediate and shape our experience of reality. They also, literally, mediate our behaviors, perceptions, desires, and expectations. An entire generation is growing up inhabiting a perpetually drugged out existence, as their constitutive environment is regulated by drugs that sedate bodies and turn minds sluggish. Our youth's ways of seeing and being in the world is being actively shaped by the diagnostic labels and mind numbing drugs. Scholars, journalists, educators, and activists must work together to marshal all the methods at their disposal to comprehend and quarantine this epidemic of injustice. 
PEDIATRIC BIPOLAR AND THE MEDIA OF MADNESS

References 
PEDIATRIC BIPOLAR AND THE MEDIA OF MADNESS

References

Andrejevic, M. (2007). Spy: Surveillance and power in the interactive era. Lawrence: University Press of Kansas.

American Psychiatric Association, A.P. (2000). Diagnostic and statistical manual of mental disorders DSM-IV-TR (4th ed.). Washington, DC: American Psychiatric Publishing, Inc.

Benkler, Y. (2006). The wealth of networks: How social production transforms markets and freedom. New Haven, CA: Yale University Press. 


\section{References}

Brody, J. E. (2007, October 23). At every age, feeling the effects of too little sleep. The New York Times. Retrieved April 19, 2010, from http://www.nytimes.com/2007/10/23/health/23brod.html

Carey, B. (2007, September 4). Bipolar illness soars as a diagnosis for the young. The New York Times. Retrieved April 19, 2010, from http://www.nytimes.com/2007/09/04/health/04psych.html

Carey, J. W. (1992). Communication as culture. Boston: Unwin Hyman.

Carpenter, T. (2009, June 6). Child's death a tragic destiny. Topeka Captial Journal. Retrieved April 19, 2010, from http://cjonline.com/news/state/2009-06-06/child's death_a tragic destiny

Castells, M. (1996). The rise of the network society. Malden, MA: Blackwell Pub.

Center for Social and Emotional Education. (n.d.). School Climate Research Summary. Retrieved April 19, 2010, from http://www.schoolclimate.org/climate/documents/school-climate-standards-

$\underline{\text { csee.pdf }}$

Child Health Care Crisis Relief Act of 2009, S. 999. $111^{\text {th }}$ Congress. (2009).

Christensen, C., Johnson, C. W., \& Horn, M. B. (2008). Disrupting class: How disruptive innovation will change the way the world learns (1st ed.). New York: McGraw-Hill.

Coleman, B. (2008). The politics of rationality: Psychiatric survivor's challenge to psychiatry. in Tactical biopolitics Art, activism, and technoscience. Beatriz da Costa and Kavita Philip, eds. Cambridge: MIT Press, 2008 
References

Couric, K. (Writer), \& Darnton, Kyra (Directory). (2007, September 30). What killed Rebecca Riley? 60 Minutes. CBS News. Retrieved April 19, 2010, from http://www.cbsnews.com/stories/2007/09/28/60minutes/main3308525.shtml

Couric, K. (Writer). (2009, May 25). The new drug of choice. CBS Evening News. CBS News. Retrieved April 19, 2010, from http://www.cbsnews.com/video/watch/?id=5038367n

Creamer, M., Mishra, R. (2007, February 7), Girl fed fatal overdoses, court told parents arraigned; lawyer questions doctor's role. The Boston Globe. Retrieved April 19, 2010, from http://www.boston.com/news/local/articles/2007/02/07/girl_fed fatal_overdoses_court told/

Crystal, S., Olfson, M., Huang, C., Pincus, H., \& Gerhard, T. (2009). Broadened use of atypical antipsychotics: Safety, effectiveness, and policy challenges. Health Affairs, 28 (5), w770-781. doi:10.1377/hlthaff.28.5.w770

Davis, L. J. (1997). The disability studies reader (1st ed.). New York: Routledge.

Dawdy, P. (2009, June 10). FDA panel recommends approval of antipsychotics for kids aged 10, older. Furious Seasons, Retrieved April 19, 2010, from http://www.furiousseasons.com/archives/2009/06/fda_panel_recommends_approval_of antipsy chotics_for_kids_aged_10_older.html

Dawdy, P. (2008, September 16). The FDA (finally) responds (sort of) to questions about Pediatric Bipolar disorder Furious Seasons. Retrieved April 19, 2010, from http://www.furiousseasons.com/archives/2008/09/the fda finally_responds sort of to questio 


\section{References}

$\underline{\text { ns_about_pediatric bipolar_disorder.html }}$

Dawdy, P. (2007). The ZyprexaKills memos. FuriousSeasons.com. Retrieved April 19, 2010, from http://furiousseasons.com/zyprexamemos

Demause, L. (1982). Foundations of psychohistory (First Edition.). New York: Creative Roots Pub.

Diller, L. (2000, March 9). Kids on drugs: A behavioral pediatrician questions the wisdom of medicating our children. Salon. Salon Media Group. Retrieved April 19, 2010, from http://www.salon.com/health/feature/2000/03/09/kid_drugs/index.html

Foucault, M. (1988). Madness and civilization: A history of insanity in the age of reason. New York: Vintage.

Freire, P. (2000). Pedagogy of the oppressed. New York: Continuum International Publishing Group.

Garviria, M. (Producer). (2008, January 8). The medicated child. Frontline. Boston MA: WGBH. Retrieved April 19, 2010, from http://www.pbs.org/wgbh/pages/frontline/medicatedchild

Hari, J. (2009, August 5). The hidden truth behind drug company profits: Ring-fencing medical knowledge is one of the great grotesqueries of our age. The Independent. Retrieved April 19, 2010, from http://www.independent.co.uk/opinion/commentators/johann-hari/johann-hari-thehidden-truth-behind-drug-company-profits-1767257.html

Harris, G. (2009, March 20). Drug maker told studies would aid it, papers say. The New York Times. 
References

Retrieved April 19, 2010, from http://www.nytimes.com/2009/03/20/us/20psych.html? $\underline{\mathrm{r}=2 \& \mathrm{ref}=\mathrm{us}}$

Harris, G. (2008, November 25). Research center tied to drug company. The New York Times Retrieved April 19, 2010, from http://www.nytimes.com/2008/11/25/health/25psych.html

Harris, G., \& Carey, B. (2008, June 8). Researchers fail to reveal full drug pay. The New York Times. Retrieved April 19, 2010, from http://www.nytimes.com/2008/06/08/us/08conflict.html

Heavy, S. (2009, June 10). US panel cautiously OKs antipsychotic drugs for kids. Reuters News. Retrieved April 19, 2010, from http://www.reuters.com/article/idUSN1046473820090610.

Hundley, K. (2009, March 29). Approval process lowers the number of kids on atypical prescriptions. St. Petersberg Times Retrieved April 19, 2010, from

http://www.tampabay.com/news/health/article987612.ece

Johnson, S. (2005). Everything bad is good for you: How today's popular culture is actually making us smarter (1st ed.). New York: Riverhead Hardcover.

Kaplan Medical, (n.d.) Specialty with top job prospects. Retrieved April 19, 2010, from http://www.kaptest.com/Physician_Assistant/Physician-Assistant/Physician-AssistantNews/specialty-with-top-job-prospects.html

Kurcinka, M. S. (1998). Raising your spirited child: A guide for parents whose child is more intense, sensitive, perceptive, persistent, energetic. New York: Harper Paperbacks.

Kweskin, S. (2010, January 29). Senator Charles Grassley broadens investigation of potential conflicts 


\section{References}

of interest. Psychiatric Times, Retrieved April 19, 2010, from http://www.psychiatrictimes.com/display/article/10168/1516707?verify=0.

Lane, C. (2009, April 7). The bipolar child is a purely American phenomenon: An interview with Philip Dawdy. Psychology Today. Retrieved April 19, 2010, from http://www.psychologytoday.com/blog/side-effects/200904/the-bipolar-child-is-purelyamerican-phenomenon-interview-philip-dawdy.

Latour, B. (2004). Politics of nature: How to bring the sciences into democracy. Cambridge, MA: Harvard University Press.

Latour, B. (2005). Reassembling the social. Oxford: Oxford University Press.

Laurance, J. (2008, January 29). Prison study to investigate link between junk food and violence. The Independent. Retrieved April 19, 2010, from http://www.independent.co.uk/life-style/healthand-families/health-news/prison-study-to-investigate-link-between-junk-food-and-violence775176.html

Lewis, B. E. (2006). Moving beyond prozac, DSM, and the new psychiatry: The birth of postpsychiatry (annotated edition.). Michigan: University of Michigan Press.

Manovich, L. (2002). The language of new media. Cambridge, MA: The MIT Press.

Martin, A., Sherwin, T., Stubbe, D., Van Hoof, T., Scahill, L., \& Leslie, D. (2002). Datapoints: Use of multiple psychotropic drugs by Medicaid-insured and privately insured children. Psychiatric Services, 53(12), 1508. doi:10.1176/appi.ps.53.12.1508

McLuhan, M. (1964) Understanding media: The extensions of man. New York: McGraw Hill. 


\section{References}

Meares A. (1959). The diagnosis of prepsychotic Schizophrenia. Lancet. I:55-58.

Morgan, D. (2009, September 30). U.S. family doctors prescribe most mental health drugs. Retrieved April 19, 2010, from http://www.reuters.com/article/healthNews/idUSTRE58T0NE20090930

Nasrallah, H. (2009, February). Psychiatry's future is here. Here are 6 trends that will affect your practice. Current Psychiatry, 8 (2), Retrieved April 19, 2010, from http://www.currentpsychiatry.com/article_pages.asp?AID=7301\&UID $=$.

Office of the Commissioner. (2007, August 22). FDA approves Risperdal for two psychiatric conditions in children and adolescents. Retrieved April 19, 2010, from http://www.fda.gov/NewsEvents/Newsroom/PressAnnouncements/2007/ucm108969.htm

Ong, W. (1982). Orality and literacy: The technologizing of the word. New Accents Series. London and New York: Methuen.

Orwell, G. (1961). 1984. New York: New American Library.

Peters, J. D. (2001). Speaking into the air: A history of the idea of communication. Chicago: University of Chicago Press.

Peters, J. D. (2009). Broadcasting and Schizophrenia. Media, Culture \& Society , $32(1), 1-18$ doi:10.1177/0163443709350101

Prodromal (n.d.). In Oxford English dictionary. Retrieved April 19, 2010, from http://dictionary.oed.com 


\section{References}

Robert, O. (2005). No place to hide: Behind the scenes of our emerging surveillance society. New York:Free Press.

Rosenberg, M. (2009, February 3). Big Pharma gone wild. Pharma Times Magazine. AlterNet. Retrieved April 19, 2010, from http://onlinejournal.com/artman/publish/article_4258.shtml.

Shekelle, P., Maglione, M., Bagley, S., Suttorp, M., Mojica, WA., Carter, J., Rolon, C., Hilton, L., Zhou, A., Chen, S., Glassman, P.. (2007, January) Comparative effectiveness of off-label use of atypical antipsychotics. Comparative Effectiveness Review No. 6. (Prepared by the Southern California/RAND Evidence-based Practice Center under Contract No. 290-02-0003.) Rockville, MD: Agency for Healthcare Research and Quality. Retrieved April 19, 2010, from www.effectivehealthcare.ahrq.gov/reports/final.cfm.

Stanley, J. and Steinhardt, B. (2003, January 15). Bigger monster, weaker chains: The growth of an American surveillance society. $A C L U$. Retrieved April 19, 2010, from http://www.aclu.org/privacy/gen/15162pub20030115.html

The No Child Left Behind Act of 2001, Pub.L. 107-110, 115 Stat. 1425. (2002, January 8).

Ücok, A., \& Gaebel, W. (2008). Side effects of atypical antipsychotics: a brief overview. World Psychiatry, 7 (1), 58-62.

U. S. Surgeon General (1999). US Surgeon General: Mental health: A report of the Surgeon General. Washington, DC: U.S. Government Printing Office. Retrieved April 19, 2010, from http://mentalhealth.samhsa.gov/features/SurgeonGeneralReport/chapter2/sec2 1.asp

Venturini, T. (2009). Diving in magma: How to explore controversies with Actor-Network Theory. 
PEDIATRIC BIPOLAR AND THE MEDIA OF MADNESS

References

Public Understanding of Science. doi:10.1177/0963662509102694

Wallace-Well, B. (2009, January 28). Bitter pill, Rolling Stone. Retrieved April 19, 2010, from http://www.rollingstone.com/politics/story/25569107/bitter_pill

Weiss, J. (2006). Urban teens write and perform resistance to school surveillance, Threat-n-Youth: Cultural Studies Responds to Violence and Education, March 31st-April 1st, 2006, Teachers College, Columbia University.

Wen, P. (2009, July 2). Psychiatrist will not be prosecuted in girl's death. The Boston Globe. Retrieved April 19, 2010, from http://www.boston.com/news/local/massachusetts/articles/2009/07/02/psychiatrist_will_not be prosecuted in_girl8217s_death/

Whitaker, R. (2003). Mad in America. Cambridge, MA: Da Capo Press.

White, T., Anjum, A., \& Schulz, S. C. (2006). The Schizophrenia prodrome. American Journal of Psychiatry, 163 (3), 376-380. doi:10.1176/appi.ajp.163.3.376

Wilens, T. E., Biederman, J., Adamson, J. J., Henin, A., Sgambati, S., Gignac, M., et al. (2008). Further evidence of an association between adolescent bipolar disorder with smoking and substance use disorders: A controlled study. Drug and Alcohol Dependence, 95 (3), 188-198.

doi:10.1016/j.drugalcdep.2007.12.016

Wilson, D. (2009, December 12). Poor children likelier to get antipsychotics. The New York Times. Retrieved April 19, 2010, from http://www.nytimes.com/2009/12/12/health/12medicaid.html

Yan, J. (2008). FDA extends Black-Box warning to all antipsychotics. Psychiatric News, 43 (14), 1-27. 


\section{References}

Retrieved April 19, 2010, from http://pn.psychiatryonline.org/cgi/content/full/43/14/1

Yung AR, McGorry PD, McFarlane CA, Jackson HJ, Patton GC, Rakkar A. (1996). Monitoring and care of young people at incipient risk of psychosis. Schizophrenic Bulletin, 22 (2), 283-303. Retrieved April 19, 2010, from http://schizophreniabulletin.oxfordjournals.org/cgi/

pmidlookup?view=long\&pmid=8782287.

Correspondence regarding this article should be directed to Jonah Bossewitch, Communications Ph.D. Candidate, Graduate School of Journalism, Columbia University, 206 West 83, New York, NY 10024. E-mail: jonah@bossewitch.net 